\title{
Performance and physiological responses of milk-fed calves to coated calcium butyrate supplementation
}

\author{
M. Nazari, K. Karkoodi ${ }^{\#}$ \& A. Alizadeh \\ Department of Animal Science, Saveh Branch, Islamic Azad University, Saveh, Iran \\ Copyright resides with the authors in terms of the Creative Commons Attribution 2.5 South African Licence. \\ See: http://creativecommons.org/licenses/by/2.5/za \\ Condition of use: The user may copy, distribute, transmit and adapt the work, but must recognise the authors and the South African Journal of \\ Animal Science.
}

\begin{abstract}
The aim of this study was to determine the effects of coated calcium butyrate (CCB) on calf performance and some blood parameters. Sixteen female Holstein calves with a mean age of $3 \pm 1 \mathrm{~d}$ were divided into two equal groups and fed a milk replacer supplemented with $3 \mathrm{~g}$ of coated calcium butyrate (CCB)/day or with no coated calcium butyrate (NCB). The calves had free access to solid feed and water. Body weight was measured at days 3,12, 24, 36 and 48 (weaning day). Respiratory rate and rectal temperature (within first 4 weeks of life), feed intake and faecal score (during the whole experimental period) were recorded daily. Rumen fluid was taken for volatile fatty acid (VFA) determination on days 33 and 48, and structural growth (rump height, withers height and hip width) was recorded on days 3, 24 and 48. Blood samples were collected on days 1, 12, 24, 36 and 48. Feed intake, average daily gain, feed conversion ratio and structural growth of calves were improved by CCB supplementation. There were no significant differences on rectal temperature, respiratory rate and faecal score between the treatments. Rumen concentration of total VFAs increased and the VFA profile was affected on days 33 and 48 by CCB supplementation. The supplementation of milk replacer of calves with coated calcium butyrate significantly increased serum concentrations of glucose, insulin and $\beta$-hydroxybutyrate. Serum concentration of cortisol in the CCB calves was numerically lower than in NCB. In conclusion, supplementation of calves' milk replacer with the coated calcium butyrate could improve calf performance.
\end{abstract}

Keywords: Pre-ruminant, volatile fatty acids, blood parameters, structural growth, Holstein calves

\# Corresponding author: karkoodi@iau-saveh.ac.ir

\section{Introduction}

In the newborn calf, the rumen is inactive and undeveloped (Heinrichs \& Jones, 2003). However, rumen development is needed to utilize solid feed such as forage and grain (Heinrichs \& Lesmeister, 2005). Transition from a pre-ruminant to a ruminant necessitates a developed rumen of adequate size (Heinrichs \& Lesmeister, 2005). Fast rumen development in young calves facilitates important changes in metabolites that may have synergistic effects on growth (Quigley et al., 1991). Organic acids, such as butyric and propionic acid, are considered the main stimulators of rumen development (Gorka et al., 2009). Researchers confirmed that additives containing butyrate and propionate may affect weaning date (Ferreira \& Bittar, 2011). It is generally accepted that the presence of VFAs is one of the effective prerequisites for rumen development (Martin et al., 1959; Gorka et al., 2011). It was demonstrated that butyric acid stimulates epithelial cell proliferation. Rumen epithelium growth in turn increases papilla length, papilla width and rumen wall thickness (Heinrichs \& Lesmeister, 2005). In the transition from pre-ruminant to ruminant, butyric acid is also a vital energy source for colon and rumen epithelial cells and has major beneficial effects on growth and feed intake, digestibility and efficiency of feed conversion (Mazzoni et al., 2008). Salts of butyric acid such as sodium and calcium butyrate are used instead of butyric acid since they are solid, more stable and less odorous (Guilloteau et al., 2009).

Gorka et al. (2009) reported that adding sodium butyrate in the milk replacer and starter of calves increased starter intake, body weight, total VFA, rumen papillae length and width. Hayat et al. (2010) 
concluded that using carboxylic acid salts such as malate in lamb diets increased body weight, concentration of serum glucose and $\beta$-hydroxybutyrate concentrations. Recently, Gorka et al. (2011) reported that using sodium butyrate in calf liquid feed indirectly affected the development of the small intestine and rumen of the calf. Therefore, the objective of this study was to evaluate the supplementation of encapsulated (rumen protected) calcium butyrate in milk replacer on some rumen and blood parameters and performance of early weaned female Holstein calves.

\section{Material and Methods}

This research was conducted between May and July at Ehiaee Agricultural and Industrial Farm (MECA, Hamadan, Iran). Sixteen $3 \pm 1$ day old female Holstein calves were randomly selected. The calves were divided into two equal groups $(\mathrm{n}=8)$ and were kept individually in pens $(1 \times 1.2 \times 1.9 \mathrm{~m})$. Treatments were (i) milk replacer with no butyrate and (ii) milk replacer containing $3 \mathrm{~g}$ coated calcium butyrate per total daily milk allowance (as recommended by the supplying company). The treatments formed a completely randomized design. The calves were fed colostrum for the first three days, after which they received $4 \mathrm{~L} / \mathrm{d}$ of the commercial milk replacer (Provimilk Super, The Netherlands), which was mixed with warm water at a 1 to 9 ratio. It was offered to the calves at 05:30, 12:30 and 19:30 each day. The milk replacer contained $220 \mathrm{~g}$ crude protein, $175 \mathrm{~g}$ crude fat, $1 \mathrm{~g}$ crude fibre, $89 \mathrm{~g}$ ash, $6 \mathrm{~g}$ calcium, $7.4 \mathrm{~g}$ phosphorus and $18 \mathrm{~g}$ lysine per $\mathrm{kg}$ on a dry matter basis, and vitamin $45000 \mathrm{IU}$ A, $4000 \mathrm{IU}$ vitamin $\mathrm{D}_{3}$ and $100 \mathrm{IU}$ vitamin $\mathrm{E}$ per $\mathrm{kg}$. The calves had free access to a commercial starter meal (Table 1) and fresh water. The encapsulated calcium butyrate $\left(\right.$ Greencab 70 Coated $^{\circledR}$ ) was provided by NutriConcept Company, Fougeres, France.

Dry matter intake (DMI) of the starter was recorded daily until weaning at day 48. Orts were removed and fresh starter was offered daily in the morning. The physical form of the faeces was scored daily during the first four weeks by three independent observers and means were recorded. Faeces were scored for physical shape as 1: firm; 2: slightly loose; 3: loose; 4: watery (Larson et al., 1977). Blood samples were taken from the jugular vein in 10-mL tubes at 14:30 on days $1,12,24,36$ and 48 . The blood samples were placed on ice immediately after collection and centrifuged at $4500 \times \mathrm{g}$ for $15 \mathrm{~min}$ at $4{ }^{\circ} \mathrm{C}$ to harvest serum. The serum was preserved at $-20^{\circ} \mathrm{C}$ for analysis of serum metabolites and hormones (Yari et al, 2010). Serum glucose was spectrophotometrically determined using a colorimetric method (GOD-PAD; Pars Azmun kit, Tehran, Iran) (Sackes, 1999). Serum $\beta$-hydroxybutyric acid (BHBA) concentration was measured with a commercial kit (Ranbut1007, UK). Serum cortisol and insulin concentrations were determined by the ELISA method, using commercial kits (RE52061, Germany) and Demeditec insulin enzyme immunoassay kits (Pars Azmun kit, Tehran, Iran), respectively.

Table1 Chemical composition of calves’ starter meal (DM basis)

\begin{tabular}{lc}
\hline Composition & g/kg \\
\hline Crude protein & 185 \\
Total digestible nutrients & 813 \\
Acid detergent fibre & 66.0 \\
Neutral detergent fibre & 155 \\
Non fibre carbohydrates & 582 \\
Ash & 60 \\
Calcium & 7.1 \\
Phosphorus & 7.0 \\
Metabolizable energy (MJ/kg) & 8.67 \\
\hline
\end{tabular}

On day 33 and after weaning (day 48) rumen fluid from eight calves (four calves per treatment) was collected at 10:30 using a stomach tube attached to a large syringe. To minimize saliva contamination, the initial $100 \mathrm{~mL}$ of the aspirated fluid was discarded. The $\mathrm{pH}$ of the second portion was measured immediately 
using a mobile $\mathrm{pH}$ meter (model $\mathrm{pH}-222$, Lutron Co, Taiwan). Rumen fluid samples were strained through four layers of cheesecloth, and $20 \mathrm{~mL}$ of the rumen fluid was collected in a hyaloid plastic container containing $1 \mathrm{~mL}$ of $5 \%$ sulphuric acid. This was then placed on an icepack in a cold box, transported to the laboratory, and stored $\left(-20{ }^{\circ} \mathrm{C}\right)$ until analysed for VFA by gas chromatography (PU4410- Philips), as described by Alizadeh et al. (2011). The calves were weighed before morning feeding on days 3, 12, 24, 36 and 48. Parameters of structural growth, including wither height, rump height and hip width, were recorded at days 3, 24 (for each calf) and at weaning. Respiration rate and rectal temperature were determined daily from birth to day 28. Rectal temperature was determined at 10:30, using a digital thermometer. Respiration rate was measured by subtle visual observation for $1 \mathrm{~min}$ three times in a $20 \mathrm{~min}$ period. The calves were weaned on day 48.

Data were analysed using the t-test procedure of SAS (2003). The initial values of some parameters such as weight were included in models as covariates to improve the analysis precision. Treatment differences were considered significant at $P \leq 0.05$.

\section{Results}

Calcium butyrate supplementation increased feed intake in the early weaned calves on days $12,24,36$, 48 and for the total period compared with the control (Table 2; $P<0.05$ ). Supplementing milk replacer with CCB significantly improved the body weight of the calves on days 12, 36, 48 and over the total period (Figure 1). Similarly, feed conversion ratio (FCR) as well as average daily gain (ADG) were altered by CCB supplementation (Table 2; $P<0.05$ ). Feed conversion ratio decreased by $31 \%$ in the calves fed calcium butyrate. Moreover, blood concentrations of glucose and insulin as well as BHBA were influenced by Ca butyrate supplementation (Table 3).

Table 2 Mean $( \pm$ SE) effects of calcium butyrate on feed intake, average daily gain and feed conversion ratio of the calves over the experimental period

\begin{tabular}{lll}
\hline Days & Milk replacer & $\begin{array}{l}\text { Milk replacer }+ \\
\text { 3 g Ca butyrate/d }\end{array}$ \\
\hline \multicolumn{3}{c}{ Feed intake $(\mathbf{g} / \mathbf{d})$} \\
$3-12$ & $121.8^{\mathrm{b}} \pm 2.32$ & $130.9^{\mathrm{a}} \pm 0.56$ \\
$13-24$ & $680.4^{\mathrm{b}} \pm 6.36$ & $726.9^{\mathrm{a}} \pm 11.67$ \\
$25-36$ & $813.2^{\mathrm{b}} \pm 26.35$ & $898.0^{\mathrm{a}} \pm 2.33$ \\
$37-48$ & $965.1^{\mathrm{b}} \pm 13.29$ & $1004.9^{\mathrm{a}} \pm 4.49$ \\
Total period & $645.1^{\mathrm{b}} \pm 8.98$ & $690.1^{\mathrm{a}} \pm 3.95$ \\
\hline \multicolumn{3}{c}{ Average daily gain $(\mathbf{g} / \mathbf{d})$} \\
$3-12$ & $251.8^{\mathrm{b}} \pm 68.5$ & $455.2^{\mathrm{a}} \pm 21.9$ \\
$13-24$ & $427.7 \pm 48.7$ & $546.3 \pm 29.8$ \\
$25-36$ & $510.7^{\mathrm{b}} \pm 46.6$ & $745.5^{\mathrm{a}} \pm 41.6$ \\
$37-48$ & $640.3 \pm 19.4$ & $692.8 \pm 43.5$ \\
Total period & $457.6^{\mathrm{b}} \pm 29.8$ & $609.9^{\mathrm{a}} \pm 15.5$ \\
\hline \multicolumn{3}{c}{ Feed conversion ratio $(\mathbf{g}$ feed/g gain) } \\
$3-12$ & $0.45 \pm 0.095$ & $0.29 \pm 0.016$ \\
$13-24$ & $1.74 \pm 0.22$ & $1.36 \pm 0.076$ \\
$25-36$ & $1.70^{\mathrm{a}} \pm 0.20$ & $1.24^{\mathrm{b}} \pm 0.084$ \\
$37-48$ & $1.51 \pm 0.051$ & $1.49 \pm 0.088$ \\
Total period & $1.38^{\mathrm{a}} \pm 0.053$ & $1.05^{\mathrm{b}} \pm 0.037$ \\
\hline
\end{tabular}




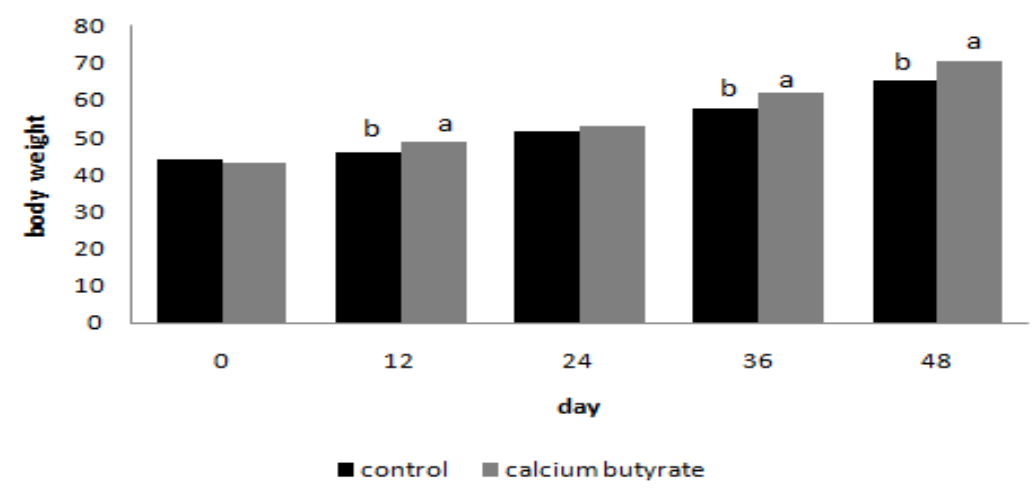

Figure1 Body weight in calves fed milk replacer (NCB) or milk replacer + 3 g Ca butyrate/d (CCB); bars within a graph with different letters 'a' or 'b' differ significantly $(P<0.05)$.

Table 3 Effects of calcium butyrate supplementation on serum glucose, insulin, BHBA and cortisol concentrations in calves at different stages of the study

\begin{tabular}{|c|c|c|}
\hline Day & Milk replacer & $\begin{array}{l}\text { Milk replacer } \\
+3 \text { g Ca butyrate/d }\end{array}$ \\
\hline & \multicolumn{2}{|c|}{ Glucose (mg/dL) } \\
\hline 1 & $103.5 \pm 3.76$ & $102.6 \pm 1.61$ \\
\hline 12 & $86.8^{\mathrm{b}} \pm 0.90$ & $96.0^{\mathrm{a}} \pm 0.84$ \\
\hline 24 & $81.2^{\mathrm{b}} \pm 0.61$ & $89.0^{\mathrm{a}} \pm 0.46$ \\
\hline 36 & $76.3^{\mathrm{b}} \pm 1.74$ & $87.1^{\mathrm{a}} \pm 2.56$ \\
\hline 48 & $69.1^{\mathrm{b}} \pm 1.95$ & $77.4^{\mathrm{a}} \pm 1.83$ \\
\hline \multirow[t]{2}{*}{ Total period } & $84.3^{\mathrm{b}} \pm 0.65$ & $91.6^{\mathrm{a}} \pm 0.90$ \\
\hline & \multicolumn{2}{|c|}{ Insulin (pmol/L) } \\
\hline 1 & $9.6 \pm 0.52$ & $9.3 \pm 0.43$ \\
\hline 12 & $3.7^{\mathrm{b}} \pm 0.79$ & $8.4^{\mathrm{a}} \pm 0.43$ \\
\hline 24 & $4.3^{\mathrm{b}} \pm 0.35$ & $7.9^{\mathrm{a}} \pm 0.37$ \\
\hline 36 & $3.2^{\mathrm{b}} \pm 0.22$ & $6.8^{\mathrm{a}} \pm 0.61$ \\
\hline 48 & $2.1^{\mathrm{b}} \pm 0.47$ & $5.9^{\mathrm{a}} \pm 0.34$ \\
\hline \multirow[t]{2}{*}{ Total period } & $4.6^{\mathrm{b}} \pm 0.27$ & $7.7^{\mathrm{a}} \pm 0.29$ \\
\hline & \multicolumn{2}{|c|}{ BHBA(mmol/L) } \\
\hline 1 & $0.05 \pm 0.00070$ & $0.06 \pm 0.0030$ \\
\hline 12 & $0.08^{\mathrm{b}} \pm 0.0035$ & $0.15^{\mathrm{a}} \pm 0.010$ \\
\hline 24 & $0.10^{\mathrm{b}} \pm 0.010$ & $0.26^{\mathrm{a}} \pm 0.022$ \\
\hline 36 & $0.18^{\mathrm{b}} \pm 0.22$ & $0.36^{\mathrm{a}} \pm 0.030$ \\
\hline 48 & $0.23^{\mathrm{b}} \pm 0.021$ & $0.56^{\mathrm{a}} \pm 0.039$ \\
\hline \multirow[t]{2}{*}{ Total period } & $0.15^{\mathrm{b}} \pm 0.011$ & $0.33^{\mathrm{a}} \pm 0.019$ \\
\hline & \multicolumn{2}{|c|}{ Cortisol ( $\mu \mathrm{g} / \mathrm{dL})$} \\
\hline 1 & $3.54 \pm 0.24$ & $3.50 \pm 0.33$ \\
\hline 12 & $2.56 \pm 0.36$ & $1.73 \pm 0.23$ \\
\hline 24 & $0.95 \pm 0.37$ & $0.71 \pm 0.16$ \\
\hline 36 & $0.40 \pm 0.16$ & $0.25 \pm 0.09$ \\
\hline 48 & $0.17 \pm 0.07$ & $0.11 \pm 0.04$ \\
\hline Total period & $1.52 \pm 0.15$ & $1.25 \pm 0.09$ \\
\hline
\end{tabular}

${ }^{\mathrm{a}, \mathrm{b}}$ Means with different superscripts in the same row differ significantly $(P<0.05)$. 
Serum concentration of cortisol tended to decrease numerically in CCB supplemented calves (Table 3; $P>0.10$ ). The average ruminal $\mathrm{pH}$ in the NCB and CCB groups was similar at both sampling dates (Table 4). However, total VFA concentration and VFA profiles differed $(P<0.05)$ between the NCB and CCB groups on day 33 and at weaning (Table 5). Supplementing milk replacer with CCB increased $(P<0.05)$ rump height, withers height and hip width compared with NCB (Figure 2). Respiratory rate and rectal temperature (Table 6) were similar $(P>0.10)$ in the two groups.

Table 4 Effects of calcium butyrate on rumen $\mathrm{pH}$ of the calves on days 33 and 48 (weaning day) of the experimental period

\begin{tabular}{ccc}
\hline Day & Milk replacer & $\begin{array}{c}\text { Milk replacer } \\
+\mathbf{3} \text { g Ca butyrate/d }\end{array}$ \\
\hline 33 & $6.24 \pm 0.04$ & $6.19 \pm 0.04$ \\
48 & $6.37 \pm 0.3$ & $6.29 \pm 0.36$ \\
\hline
\end{tabular}

Table 5 Effect of calcium butyrate on the volatile fatty acid (VFA) pattern and total VFA in the rumen of the calves on days 33 and 48 of the experiment

\begin{tabular}{lllll}
\hline \multirow{2}{*}{ VFA } & \multicolumn{2}{c}{ Milk replacer } & \multicolumn{2}{c}{ Milk replacer + 3 g Ca butyrate/d } \\
\cline { 2 - 5 } & $\mathbf{3 3}^{\text {th }}$ day & $\mathbf{4 8}^{\text {th }}$ day & $\mathbf{3 3}^{\text {th }}$ day & $\mathbf{4 8}^{\text {th }}$ day \\
\hline Acetate $(\mathrm{mmol} / \mathrm{L})$ & $40.6^{\mathrm{b}} \pm 1.45$ & $60.6^{\mathrm{b}} \pm 2.32$ & $60.4^{\mathrm{a}} \pm 2.75$ & $77.7^{\mathrm{a}} \pm 2.00$ \\
Propionate $(\mathrm{mmol} / \mathrm{L})$ & $18.6^{\mathrm{b}} \pm 0.43$ & $27.1^{\mathrm{b}} \pm 0.52$ & $24.7^{\mathrm{a}} \pm 0.56$ & $38.7^{\mathrm{a}} \pm 1.08$ \\
Butyrate $(\mathrm{mmol} / \mathrm{L})$ & $6.6^{\mathrm{b}} \pm 0.48$ & $9.4^{\mathrm{b}} \pm 0.62$ & $8.9^{\mathrm{a}} \pm 0.54$ & $12.8^{\mathrm{a}} \pm 0.46$ \\
Valerate $(\mathrm{mmol} / \mathrm{L})$ & $2.2^{\mathrm{b}} \pm 0.15$ & $2.7^{\mathrm{b}} \pm 0.09$ & $3.2^{\mathrm{a}} \pm 0.06$ & $3.4^{\mathrm{a}} \pm 0.20$ \\
Isovalerate $(\mathrm{mmol} / \mathrm{L})$ & $1.09^{\mathrm{a}} \pm 0.06$ & $1.5 \pm 0.18$ & $0.9^{\mathrm{b}} \pm 0.03$ & $1.1 \pm 0.07$ \\
Isobutyrate $(\mathrm{mmol} / \mathrm{L})$ & $0.7^{\mathrm{a}} \pm 0.02$ & $0.7^{\mathrm{a}} \pm 0.03$ & $0.6^{\mathrm{b}} \pm 0.02$ & $0.6^{\mathrm{b}} \pm 0.02$ \\
Total VFA $(\mathrm{mmol})$ & $70.1^{\mathrm{b}} \pm 1.59$ & $102.3^{\mathrm{b}} \pm 2.57$ & $99.0^{\mathrm{a}} \pm 3.39$ & $134.5^{\mathrm{a}} \pm 2.64$ \\
\end{tabular}

${ }^{\mathrm{a}, \mathrm{b}}$ Means with different superscripts in the same row differ significantly $(P<0.05)$.

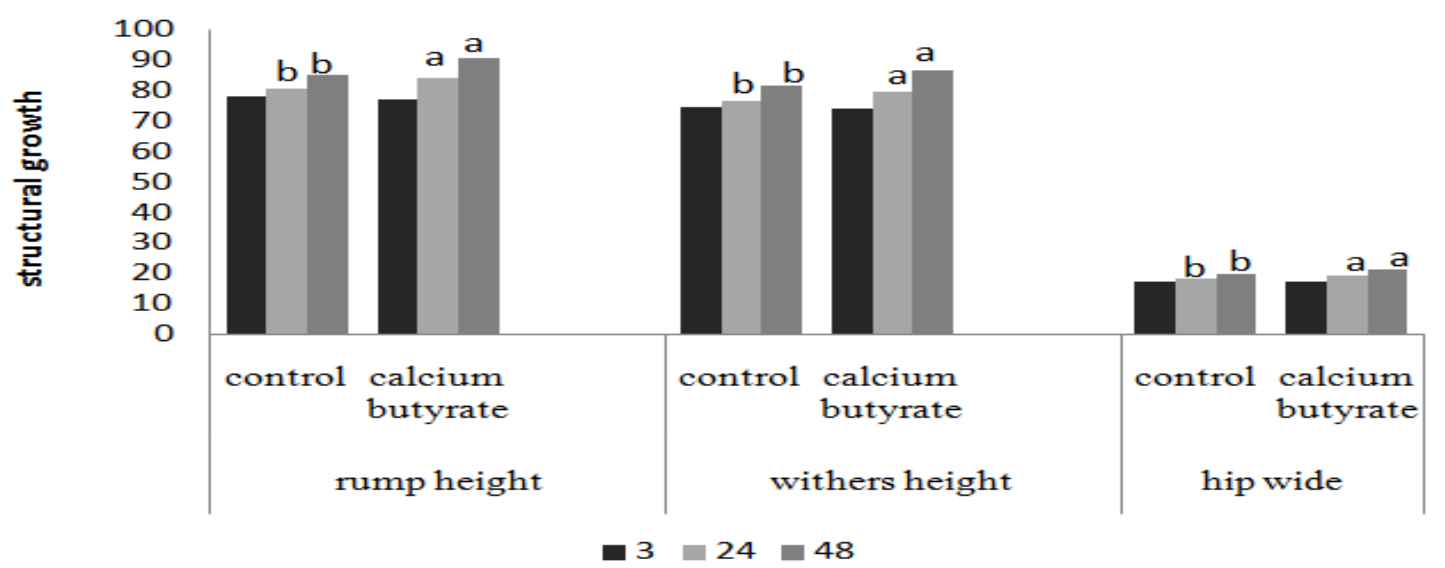

Figure 2 Structural growth in calves fed milk replacer (NCB) or milk replacer + $3 \mathrm{~g}$ Ca butyrate/d (CCB); bars within a graph with different letters 'a' and 'b' differ significantly $(P<0.05)$. 
Table 6 Means ( \pm SE) effects of calcium butyrate on respiratory rate (number/min) and rectal temperature $\left({ }^{\circ} \mathrm{C}\right)$

\begin{tabular}{ccc}
\hline Day & Milk replacer & $\begin{array}{c}\text { Milk replacer }+ \\
\text { 3 g Ca butyrate/d }\end{array}$ \\
\hline & \multicolumn{2}{c}{ Respiratory rate } \\
1 & $41.0 \pm 1.41$ & $42.8 \pm 1.35$ \\
2 & $32.8 \pm 2.01$ & $32.1 \pm 1.2$ \\
3 & $33.0 \pm 1.15$ & $30.3 \pm 1.23$ \\
4 & $37.5 \pm 3.32$ & $36.2 \pm 1.81$ \\
\hline & \multicolumn{2}{c}{ Rectal temperature } \\
2 & $38.5 \pm 0.04$ & $38.5 \pm 0.05$ \\
3 & $38.6 \pm 0.07$ & $38.7 \pm 0.03$ \\
4 & $38.6 \pm 0.19$ & $38.6 \pm 0.07$ \\
& $38.6 \pm 0.20$ & $38.7 \pm 0.10$ \\
\hline
\end{tabular}

\section{Discussion}

This study provides compelling evidence of the effectiveness of Ca butyrate in improving the performance of early weaned calves. That CCB supplementation increased the intake of the starter meal suggests that this product has a major impact on feed intake. This has been reported by Martin et al. (1959) and Gorka et al. (2009), who stated that the inclusion of sodium butyrate in the diet of calves can have a positive effect on starter intake. It seems as if an increased DMI is a typical response to butyrate (calcium or sodium) supplementation, and this positive effect is observed during the suckling period, thus preparing the rumen for early weaning. The current study provided evidence that CCB, at $3 \mathrm{~g} / \mathrm{d}$ in milk replacer, can be used effectively in calf diets. Elevated body weight was the consequence of the increased starter intake in the calves. In agreement with our findings, a recent study in Egypt (Hayat et al., 2010) demonstrated that body weight increased in lambs fed malate. Similarly, CCB-supplemented calves had a lower FCR than NCB calves. These findings are in agreement with those reported by Piva et al. (2002) and Hill et al. (2007), who included sodium butyrate in piglets' and calves' diets, respectively. Feed intake, ADG and rumen development are critical in young calves where solid DMI is often insufficient. It can be concluded that calcium butyrate can improve all performance parameters by providing butyrate as a major stimulator of rumen development. The improvement in calf performance, along with a linear increase in blood BHBA concentration, suggests that the feeding CCB increased butyrate exposure to tissues. This was indicative of the improved metabolism and insulin function, which increased energy status and performance. Blood glucose concentration was significantly different between the NCB- and CCB-treated calves. It has been suggested that propionate is the essential substrate for glucose synthesis in ruminants (Annison et al., 1963). Indeed, the elevated serum concentrations of glucose and insulin were accompanied with an increased propionate concentration in the CCB calves. It has been reported that the serum concentrations of insulin and glucose follow the same pattern (Young et al., 1970). Moreover, Lane \& Jesse (1997) observed that intra ruminal infusion of VFA resulted in an increased blood insulin concentration, and suggested that insulin may stimulate mitosis in the rumen epithelium. There was a significant difference in serum concentration of insulin between the control calves and those that were fed CCB. This provides support for the conclusion that using a butyrate source could lead to positive responses in insulin concentration, rumen development and calf performance. Interestingly, BHBA concentration in serum increased $(P<0.05)$ in the CCB supplemented group compared with the NCB group. A simple explanation for the increased serum BHBA concentration in CCB group was daily butyrate intake. Another putative consequence of elevated serum concentration of BHBA, which is confirmed by Ferreira \& Bittar (2011) and Yari et al. (2010), is that the increased starter intake resulted in a higher rumen VFA production.

Cortisol has being reported as an alarm mechanism and enables the body to overcome stressful conditions (Van Heugten \& Spears, 1997). Serum cortisol concentration was not affected by CCB and this is 
in agreement with an earlier study by Hammon et al. (2002). Moreover, this response may reflect favourable living conditions for the calves during the current experiment.

As expected, encapsulated CCB did not alter rumen $\mathrm{pH}$, because this product is in a coated form and will be released in the small intestines. Our findings also confirm the results of Gorka et al. (2009) in calves and Smulikowska et al. (2009) in chickens, who reported that rumen, stomach and crop pH did not change when organic acid salts were consumed. Some changes were observed in total VFA concentration and proportions following an increase in DMI (Van Soest, 1994). The CCB supplemented calves had higher daily feed intake than the NCB group. Thus, our VFAs data support the theory that elevating DMI may increase VFA concentrations and thus rumen development, particularly in young calves. In ruminants, some changes were observed in total fatty acid concentrations and relative proportions of VFA after an increase in their DMI (Van Soest, 1994). The CCB calves had higher daily intakes than the NCB calves. Thus, our VFA data support the theory that elevating DMI may improve VFA concentration and rumen development, particularly in young calves. Ferreira \& Bittar (2011) demonstrated that physical traits such as wither height, heart girth and hip width of calves improved when their milk replacer was supplemented with sodium butyrate, which conforms with the results of present study. Increase in DMI and improvement of physical traits suggest that CCB, together with high-quality milk replacer and starter, has a major impact on calves' growth within a short period of time. Furthermore, lack of changes in faecal scores, rectal temperature and respiration rate suggests that the calves did not experience stressful rearing condition.

\section{Conclusion}

Supplementing Ca butyrate significantly increased the structural growth, as well as serum concentrations of glucose, insulin and BHBA in calves. An industrial impetus for the current study was that supplementing calves' milk replacers with $3 \mathrm{~g} / \mathrm{d}$ of encapsulated $\mathrm{Ca}$ butyrate (based on the producing company's recommended dose) improved their rumen development and general health.

\section{Acknowledgements}

Authors are grateful for financial assistance from Kimiya Darou Mehr Co., Tehran, Iran. The authors also express their appreciation to the management and staff of Ehiaee Agricultural and Industrial Farm for their help and animal care.

\section{References}

Alizadeh, A.R., Alikhani, M., Ghorbani, G.R., Rahmani, H.R., Rashidi, L. \& Loor, J.J., 2011. Effects of feeding roasted safflower seeds (variety IL-111) and fish oil on dry matter intake, performance and milk fatty acid profiles in dairy cattle. J. Anim. Physiol. Anim. Nutr. (DOI: 10.1111/j.14390396.2011.01165.x).

Annison, E.F., Leg, R.A., Lindsay, D.B. \& White, R.R., 1963. The metabolism of acetic acid, propionic acid and butyric acid in sheep. J. Biol. Chem. 88, 248-252.

Ferreira, L.S. \& Bittar, C.M.M., 2011. Performance and plasma metabolites of dairy calves fed starter containing sodium butyrate, calcium propionate or sodium monensin. Anim. J. 5, 239-245.

Gorka, P., Kowalski, Z.M., Pietrzak, P., Kotunia, A., Jagusiak, W. \& Zabielski, R., 2011. Is rumen development in newborn calves affected by different liquid feeds and small intestine development? J. Dairy Sci. 94, 3002-3013.

Gorka, P., Kowalski, Z.M., Pietrzak, P., Kotunia, A., Kiljanczyk, R., Flaga, J., Holst, J.J., Guilloteau, P. \& Zabielski, R., 2009. Effect of sodium butyrate supplementation in milk replacer and starter diet on rumen development in calves. J. Physiol. Pharmacol. 60 (Suppl. 3), 47-53.

Guilloteau, P., Zabielski, R., David, J.C., Blum, J.W., Morisset, J.A., Biernat, M., Woliński, J., Laubitz, D. \& Hamon, Y., 2009. Sodium-butyrate as a growth promoter in milk replacer formula for young calves. J. Dairy Sci. 92, 1038-1049.

Hammon, H. M., Schiessler, G., Nussbaum, A. \& Blum, J.W., 2002. Feed intake patterns, growth performance, and metabolic and endocrine traits in calves fed unlimited amounts of colostrum and milk by automate, starting in the neonatal period. J. Dairy Sci. 85, 3352-3362. 
El Nour Hayat, H.M., Whba, T.M., Ibrahim, M.A. \& Anwer, A.M., 2010. Impact of supplementation with carboxylic acid salt on growth rate and some blood biochemical values in male lambs. Global Veterinaria 1, 90-96.

Heinrichs, A.J. \& Jones, C.M., 2003. Feeding the Newborn Dairy Calf. The Pennsylvania State University. $1-23$.

Heinrichs, A.J. \& Lesmeister, K.E., 2005. Rumen development in the dairy calf. In: Calf and Heifer Rearing. Ed. Garnworthy, P.C., Nottingham University Press, Nottingham, UK. pp. 53-66.

Hill, T.M., Aldrich, J.M., Schlotterbeck, R.L. \& Bateman, H.G., 2007. Effects of changing the fatty acid composition of calf starters. Prof. Anim. Sci. 23, 665-671.

Lane, M.A. \& Jesse, B.W., 1997. Effect of volatile fatty acid infusion on development of the rumen epithelium in neonatal sheep. J. Dairy Sci. 80, 740-746.

Larson, L.L., Owen, F.G., Albright, J.L., Appleman, R.D., Lamb, R.C. \& Muller, L.D., 1977. Guidelines toward more uniformity in measuring and reporting calf experimental data. J. Dairy Sci. 60, 989-991.

Martin, W.G., Ramsey, H.A., Matrone, G. \& Wise, G.H., 1959. Responses of young calves to a diet containing salts of volatile fatty acids. J. Dairy Sci. 42, 1377-1386.

Mazzoni, M., Le Gall, M., De Filippi, S., Minieri, L., Trevisi, P., Wolinski, J., Lalatta-Costerbosa, G., Lallès, J-P., Guilloteau, P. \& Bosi, P., 2008. Supplemental sodium butyrate stimulates different gastric cells in weaned pigs. J. Nutr. 138, 1426-1431.

Piva, A., Morlacchini, M., Casadei, G., Gatta, P.P., Biaji, G. \& Prandin, A., 2002. Sodium butyrate improves growth performance of weaned piglets during the first period after weaning. Italian J. Anim. Sci. 1, 35-41.

Quigley III, J.D., Caldwell, L.A., Sinks, G.D. \& Heitmann, R.N., 1991. Changes in blood glucose, nonesterified fatty acids, and ketones in response to weaning and feed intake in young calves. J. Dairy Sci. 74, 250-257.

Sackes, D.B., 1999. Carbohydrates. In: Textbook of Clinical Chemistry. (3rd. ed.), Eds Burtis, C.A. \& Ashwood, E.R., Philadelphia, W.B. Saunders Co. pp. 705-808.

SAS, 2003. Statistical Analysis Systems user's guide. (9.0) SAS Institute Inc., Raleigh, North Carolina, USA.

Smulikowska, S., Czerwinski, J., Mieczkowska, A. \& Jankowiak, J., 2009. The effect of fat- coated organic acid salts and a feed enzyme on growth performance, nutrient utilization in broiler chickens. J. Anim. Feed Sci. 18, 478-479.

Van Heugten, E.V. \& Spears, J.W., 1997. Immune response and growth of stressed weanling pigs fed diets supplemented with organic or inorganic forms of chromium. J. Anim. Sci. 75, 409-416.

Van Soest, P.J., 1994. Nutritional Ecology of the Ruminant, Cornell University Press, Ithaca, NY, USA.

Yari, M., Nikkhah, A., Alikhani, M., Khorvash, M., Rahmani, H. \& Ghorbani, G.R., 2010. Physiological calf responses to increased chromium supply in summer. J. Dairy Sci. 93, 4111-4120.

Young, J.W., Otchere, E.O., Trenkle, A. \& Jacobson, N.L., 1970. Effect of age on glucose, reducing sugars and plasma insulin in blood of milk-fed calves. J. Nutr. 100, 1267-1273. 